\title{
A cross sectional study to evaluate indications and outcomes of caesarean section in a district hospital of West Bengal
}

\author{
Pratima Maurya ${ }^{1 *}$, Sandeep Saini², Bhawna Saini' ${ }^{3}$, Mohit Kumar ${ }^{4}$, \\ Ajit Kumar Adhya ${ }^{1}$, Ranjit Kumar Mondal ${ }^{1}$
}

\author{
${ }^{1}$ Department of Obstetrics and Gynecology, North 24 Parganas District Hospital, Barasat, West Bengal, India \\ ${ }^{2}$ Department of Nephrology, AIIMS, Rishikesh, Uttrakhand, India \\ ${ }^{3}$ Department of Pharmacology, AIIMS, Rishikesh, Uttrakhand, India \\ ${ }^{4}$ Department of Anesthesia, AIIMS, Rishikesh, Uttrakhand, India
}

Received: 22 June 2021

Accepted: 16 July 2021

\author{
*Correspondence: \\ Dr. Pratima Maurya, \\ E-mail: dr.pratimamaurya@gmail.com
}

Copyright: () the author(s), publisher and licensee Medip Academy. This is an open-access article distributed under the terms of the Creative Commons Attribution Non-Commercial License, which permits unrestricted non-commercial use, distribution, and reproduction in any medium, provided the original work is properly cited.

\begin{abstract}
Background: There is drastic rise in caesarean section (CS) rate worldwide in last decade as compared to optimal CS rate $(10-15 \%)$ recommendation by WHO. This study was conducted to assess incidence and feto-maternal outcome in CS delivery.

Methods: A cross-sectional study was conducted in pregnant women admitted over one year from September 2017August 2018 in West Bengal. Demographic details and indication of CS were recorded along with documentation of feto-maternal outcomes. Statistical analysis was performed with help of Epi Info (TM) 7.2.2.2. Z-test and corrected Chi square $(\chi 2)$ test. $\mathrm{p}<0.05$ was considered to be statistically significant.

Results: Out of total 10831 deliveries, 2914 (27\%) women underwent CS. Demographic analysis shows maximum number of patients to be between $20-25 y e a r s ~(51.7 \%)$, rural $(58 \%)$, primigravida $(51.3 \%)$, term pregnancy $(87.7 \%)$. Non-progression of labour or NPL $(45 \%)$ was most common indication of CS followed by previous CS (26.2\%) and fetal distress $(17.9 \%)$. Post CS wound infection was seen in $33(1.1 \%)$ women. Two maternal deaths were recorded. Still born was documented in $0.8 \%$ while $6.8 \%$ fetus were referred to paediatric ICU.

Conclusions: Rise in CS rates was mainly reported in 20-25 years age group, rural patients, in term pregnancy of primigravida patients. Most common indication for CS was NPL followed by previous CS and fetal distress. Mostly patients showed no complication in postpartum period. Only few patients had wound infection, hysterectomy and postpartum haemorrhage. More than $99 \%$ fetus survived without any complications.
\end{abstract}

Keywords: Caesarean section rates, Caesarean section indications, Fetal distress

\section{INTRODUCTION}

Caesarean section in medically justified cases can prevent maternal and perinatal mortality and morbidity. In 1985, WHO has considered an optimal rate of CS to be between $10 \%$ and $15 \% .^{1}$ As per WHO review, CS rates above 9$16 \%$ are not associated with decrease in maternal and fetal mortality. Many professional groups are questioning WHO recommended optimal CS rate by suggesting that lowering the CS rate may be more harmful for mother and fetus. ${ }^{2}$ There has been an expeditious rise in the CS rate throughout the world. There is worldwide variation in the CS rate ranging from $4-65 \%$ in USA with some countries like Brazil going as high as $55.6 \%{ }^{3,4}$ Similar rising trends in CS rate from $21.8 \%$ in $1993-94$ to $25.4 \%$ in $1998-99$, was also noted in study conducted by Indian Council of Medical Research. ${ }^{5}$ The aim of the study was to determine $\mathrm{CS}$ rate at district hospital of West Bengal. It also assessed 
indications of CS and its outcome in terms of fetal and maternal morbidity and mortality.

\section{METHODS}

An observational study was conducted in pregnant women admitted over one year from September 2017- August 2018 in department of Obstetrics and gynaecology in a referral centre of Barasat, West Bengal. All patients underwent history taking, clinical examination and necessary investigations on admission. The approval was started after obtaining approval from the institutional ethical committee. Decision to perform CS was taken after examination by senior consultants as per the indications given below- Cephalo-pelvic disproportion (CPD); pelvic mass causing obstruction; advance carcinoma of cervix; vaginal obstruction; previous caesarean section; fetal distress (FD); non-progression of labour (NPL); dystocia; central placental praevia; Antepartum haemorrhage (APH); malpresentation; multiple pregnancy; bad obstetric history $(\mathrm{BOH})$; severe pre-eclampsia; and eclampsia

Informed consent was taken prior to study. Those pregnant women who refused to participate or underwent CS for intrauterine fetal death (IUFD) were excluded. Data was collected including age, gravida, parity and indication of CS. Total delivery including normal vaginal delivery, caesarean section, instrumental delivery and vaginal birth after caesarean section (VBAC) was recorded. Maternal death including cause of death was also documented. Fetal gestational age along with birth weight was documented. Data regarding transfer to sick new born care unit (SNCU) along with fetal death was recorded.

Statistical analysis was performed with help of Epi Info (TM) 7.2.2.2. Z-test (standard normal deviate) was used to test the significant difference between two proportions Chi-square $\left(\chi^{2}\right)$ test was used to test the association between different study variables. Corrected Chi-square $\left(\chi^{2}\right)$ was used to test the association between different study variables in case of one of the cell frequencies found to be less than 5 . Odds ratio (OR) with $95 \%$ confidence interval $(\mathrm{CI})$ was calculated to measure the different risk factor. $\mathrm{p}<0.05$ was considered to be statistically significant.

\section{RESULTS}

During study period a total 10831 deliveries were performed in this hospital. Out of total deliveries, 2914 (27\%) patients underwent CS. Baseline characteristics of patients are shown in Table 1 . Most patients were in the age group between 20-25 years (51.7\%) which was significantly higher than other age group ( $Z=4.16$; $\mathrm{p}<0.0001)$. The mean age of the patients was $23.24 \pm 4.28$ years with range 14-45 years. Test of proportion showed that patients $(85.0 \%)$ from rural area was significantly higher than that of the patients from urban area $(15.0 \%)$ $(Z=9.89 ; p<0.001) .87 .7 \%$ of the patients were with period of gestation $>37$ weeks which was significantly higher
( $\mathrm{Z}=10.69 ; \mathrm{p}<0.0001)$. The mean period of gestation was $38.72 \pm 1.10$ weeks with range $32-41$ weeks. $51.3 \%$ of the patients were primigravida which was significantly higher $(\mathrm{Z}=2.15 ; \mathrm{p}=0.036)$. Twelve women were grand multiparous ( $\geq 4$ parity).

Non-progressive labour or NPL (45.5\%) was the most common indication of CS which was significantly higher than other indications $(\mathrm{Z}=2.84 ; \mathrm{p}<0.001)$ (Table 2). The percentage of women who underwent CS has been summarized in Figure 1. Five forty $(5 \%)$ women underwent VBAC in our study. Forceps was used to deliver in $118(1 \%)$ women as mentioned in Figure 2.

Majority of the patients had no complication (98.8\%) which was significantly higher $(Z=13.8 ; \mathrm{p}<0.0001)$. Thirty-three patients $(1.1 \%)$ had wound infection. Hysterectomy was done in two patients. One patient had post-partum haemorrhage. $99.46 \%$ of the patients had singleton pregnancy which was significantly higher $(\mathrm{Z}=13.36$; $\mathrm{p}<0.0001)$. Majority of the patients were discharged in stable condition $(99.91 \%)$ which was significantly higher outcomes $(\mathrm{Z}=14.1 ; \mathrm{p}<0.001)$. During the study period two $(0.06 \%)$ patients died in post CS, one died due to eclampsia and other died due to puerperal sepsis. One patient was transferred to critical care unit in view of the neurological complications after eclampsia.

The mean birth weight of fetus was $2774.79 \pm 453.90 \mathrm{~g}$ with range 1250-5035 g. Majority of the neonates had birth weight between 2001-2999 g (65.6\%) which was significantly higher $(Z=5.61 ; p<0.001)$. Seven $(0.2 \%)$ of the neonates were having very low birth weight. Sixteen $(0.54 \%)$ fetus had birth weight more than four $\mathrm{kg}$. In our study $23(0.8 \%)$ fetus were still born. Of these 23 women $\mathrm{CS}$ was performed due to fetal distress $(\mathrm{N}=7)$, previous $\mathrm{CS}$ $(\mathrm{N}=6)$, malpresentation $(\mathrm{N}=6)$, APH $(\mathrm{N}=2), \mathrm{PIH}(\mathrm{N}=2)$.

\section{Assessment of risk factors}

Corrected Chi square $\left(\chi^{2}=3.97\right)$ test showed significant association between maternal age and maternal complication $(\mathrm{p}=0.044)$. Thus, maternal complications were mostly prevalent among the patients with age $<18$ years. The risk of maternal complications was 3.09 times more among the patients with age $<18$ years as compared to the patients with age $\geq 18$ years and the risk was significant [OR-3.09 (1.03, 10.31); p=0.044]. Corrected Chi square $\left(\chi^{2}=0.69\right)$ test showed no significant association between maternal age and fetal outcomes $(\mathrm{p}=0.70)$. Thus, fetal outcomes were more or less equally distributed over the maternal age. Corrected Chi square $\left(\chi^{2}=0.29\right)$ test showed no significant association between maternal age and fetal birth weight and fetal outcome $(\mathrm{p}=0.58)$. However, LBW babies (29.2\%) were mostly prevalent among the patients with age $<18$ years. The risk of LBW babies was 1.13 times more among the patients with age $<18$ years as compared to the patients with age $\geq 18$ years but the risk was not significant [OR-1.13 $(0.71,1.81)$; $\mathrm{p}=0.58]$. Corrected Chi square $\left(\chi^{2}=0.46\right)$ test showed no 
significant association between gestational age (GA) and maternal complications $(\mathrm{p}=0.99)$. Thus, maternal complications were more or less equally distributed over the GA of the patients. Corrected Chi square $\left(\chi^{2}=3.73\right)$ test showed that there was no significant association between GA and fetal birth weight $(\mathrm{p}=0.15)$. Thus, fetal birth weight was more or less equally distributed over the GA of the patients. Corrected Chi square $\left(\chi^{2}=2.01\right)$ test showed that there was no significant association between period of gestation and fetal outcomes $(p=0.73)$. Thus, fetal outcomes were more or less equally distributed over the GA of the patients.

Table 1: Baseline characteristic of patients underwent CS.

\begin{tabular}{|lll|}
\hline Group & Number & Percentage (\%) \\
\hline Age group (years) & & 21.1 \\
\hline $14-19$ & 1506 & 51.7 \\
\hline $20-25$ & 675 & 23.2 \\
\hline $26-31$ & 103 & 3.5 \\
\hline $32-37$ & 14 & 0.5 \\
\hline$>37$ & & \\
\hline Residence & 2476 & 85.0 \\
\hline Rural & 438 & 15.0 \\
\hline Urban & & \\
\hline Gestational age (years) & 4 & 0.1 \\
\hline$<34$ & 353 & 12.1 \\
\hline $34-37$ & 2557 & 87.7 \\
\hline$>37$ & & \\
\hline Gravida & 1495 & 51.3 \\
\hline 1 & 1054 & 36.2 \\
\hline 2 & 271 & 9.3 \\
\hline 3 & 94 & 3.2 \\
\hline$\geq 4$ & & 63.9 \\
\hline Postpartum contraception & 1863 & 29.9 \\
\hline IUCD & 871 & 6.2 \\
\hline Ligation & 180 & \\
\hline No & & 99.46 \\
\hline Number of fetus & 2896 & 0.51 \\
\hline Single & 17 & 0.03 \\
\hline Twin & 1 & 0.2 \\
\hline Triplet & & 4.1 \\
\hline Fetal birth weight (g) & 7 & 24.4 \\
\hline$<1500$ & 120 & 31.2 \\
\hline $1500-2000$ & 716 & 30.1 \\
\hline $2001-2499$ & 1208 & \\
\hline $2500-2999$ & 882 & \\
\hline$\geq 3000$ & & \\
\hline
\end{tabular}

Table 2: Distribution of indication of CS of the patients.

\begin{tabular}{|lll|}
\hline Indication of CS & Number & Percentage $(\%)$ \\
\hline NPL & 1327 & 45.5 \\
\hline Previous CS & 763 & 26.2 \\
\hline Fetal distress & 522 & 17.9 \\
\hline CPD & 101 & 3.5 \\
\hline Malpresentation & 83 & 2.8 \\
\hline Pre-eclampsia & 47 & 1.6 \\
\hline Eclampsia & 24 & 0.8 \\
\hline APH & 16 & 0.5 \\
\hline Multiple pregnancy & 14 & 0.5 \\
\hline BOH & 6 & 0.2 \\
\hline Dystocia & 6 & 0.2 \\
\hline
\end{tabular}




\begin{tabular}{|lll|}
\hline Indication of CS & Number & Percentage $(\%)$ \\
\hline Placenta praevia & 3 & 0.1 \\
\hline Vaginal obstruction & 2 & 0.1 \\
\hline Total & 2914 & 100 \\
\hline
\end{tabular}

Table 3: Rising trend of CS rate in India.

\begin{tabular}{|c|c|c|}
\hline Author & Regions & CS rates (\%) \\
\hline \multirow{3}{*}{ Manjulatha B et al } & \multirow{3}{*}{ Andhra Pradesh } & 2002- 16.60 \\
\hline & & 2007- 18.20 \\
\hline & & 2012- 22.40 \\
\hline \multirow[t]{2}{*}{ Singh G et al } & \multirow[t]{2}{*}{ Haryana } & 2007- 30 \\
\hline & & 2012- 51.1 \\
\hline \multirow{3}{*}{ Shiba M et al } & \multirow{3}{*}{ Mumbai } & 2001- 17.15 \\
\hline & & 2006- 23.47 \\
\hline & & 2011- 28.93 \\
\hline \multirow{2}{*}{ Rahman $\mathrm{H}$ et al } & \multirow{2}{*}{ Sikkim } & 2001- 10.1 \\
\hline & & 2011- 19.4 \\
\hline \multirow{2}{*}{ Sarkar D et al } & \multirow{2}{*}{ West Bengal } & 2011- 28.32 \\
\hline & & 2015- 39.5 \\
\hline
\end{tabular}

Table 4: Comparison of CS rates with different regions of India.

\begin{tabular}{|llll|}
\hline Authors & Regions & Study periods & CS rates $(\%)$ \\
\hline Present study & West Bengal & September 2017-August 2018 & 27 \\
\hline Preetkamal et al & Punjab & May 2015-April 2016 & 33.20 \\
\hline Yadav et al & Haryana & April 2015-March 2016 & 21.60 \\
\hline Saxena et al & Uttarakhand & January 2015-December 2015 & 31.40 \\
\hline Sarma et al & Assam & January 2015-December 2015 & 27.60 \\
\hline Padmaleela et al & Andhra Pradesh & April 2011-March 2012 & 31 \\
\hline
\end{tabular}

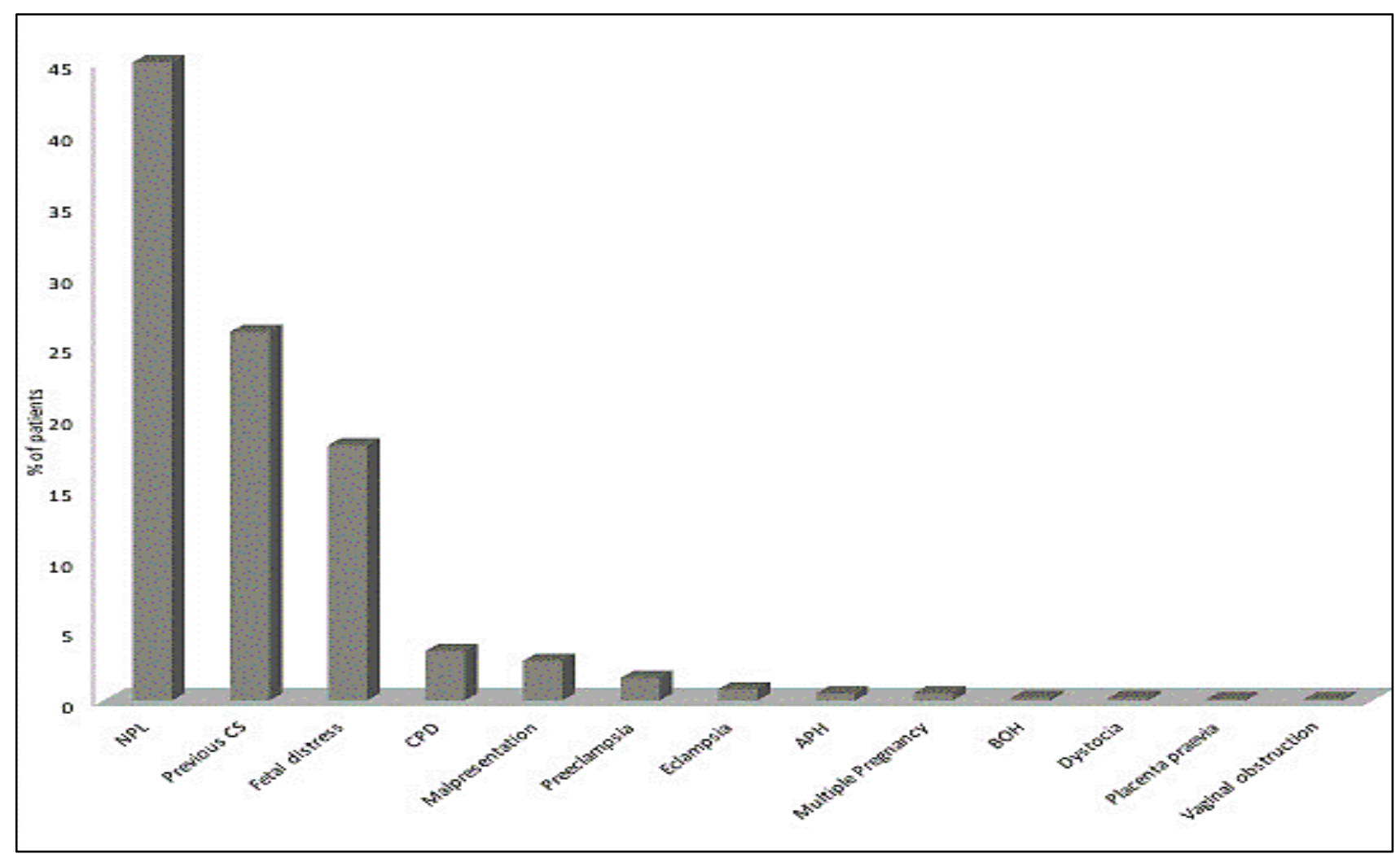

Figure 1: Indications of CS. 


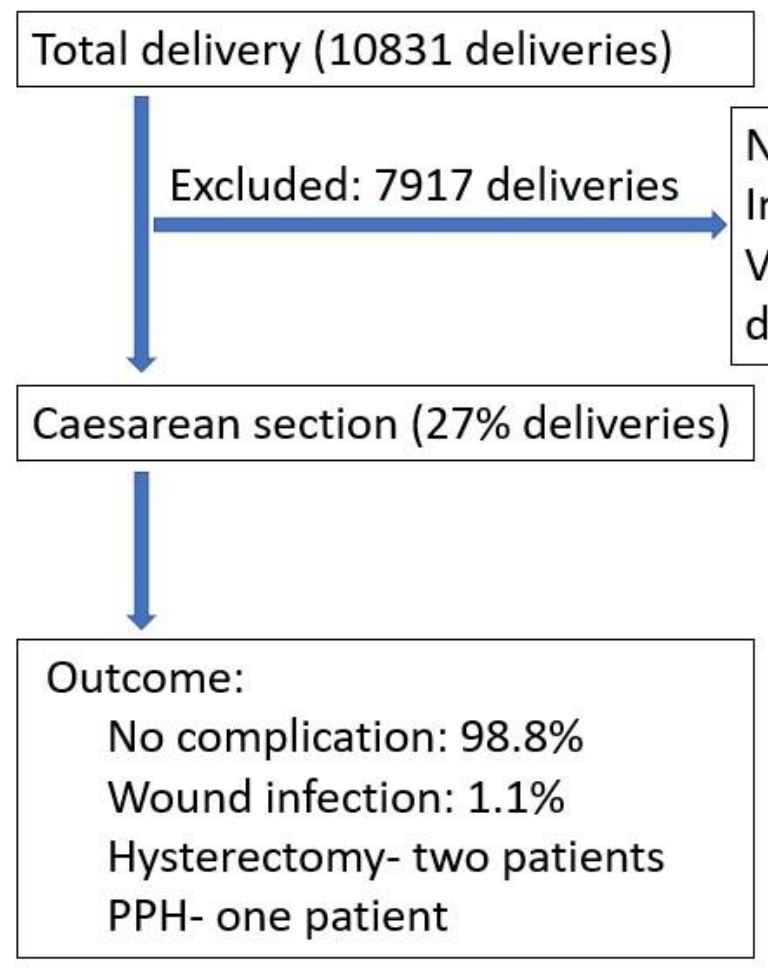

Figure 2: Study participants undergoing caesarean section and it's outcomes.

\section{DISCUSSION}

In this study, 10831 women delivered at our institution reveals large number of women attending for institutional delivery similar to Assam. This upward trends in the institutional deliveries from $39 \%$ in $2005-06$ to $79 \%$ in 2015-16 seen in national family health survey 4 (NFHS 4) 2015-16 also support upswing in delivery at our hospital. ${ }^{6}$ With the introduction of Janani Suraksha Yojana as monetary benefits, the rates of institutional birth have increased from pre-programme average of $20 \%$ to $49 \%$ in 5 years. $^{7}$

The CS rate in our study is similar to that of Asian countries $(27.3 \%) .{ }^{8}$ As per NFHS- 4 there is rise in CS rate, from $10.2 \%$ to $23.8 \%$ in West Bengal. ${ }^{6}$ Similar rising trend in CS rate are seen in various parts of India as shown in table-3. ${ }^{9-13} \mathrm{CS}$ rate in our study is comparable to other studies from other regions of India as shown in table-4. ${ }^{14-}$ ${ }^{18}$ The potential reasons for increment in CS rates are high numbers of referrals of complicated obstetric cases, low rates of instrumental delivery and VBAC.

Higher CS rates in the women of age group 20-25 years $(51.7 \%)$ similar to other studies reflecting the age of maximum fertility in Indian. This study also reflects that the age at first child birth is increasing with time. In our study $21.1 \%$ teenagers underwent CS which is comparable to $24.17 \%$ reported from south 24 Parganas, West Bengal. ${ }^{19}$ In West Bengal around $50 \%$ of women are married before the legal age 18 years may be a reason for this high teenage pregnancy. ${ }^{6}$ Our study shows more than half $(51.3 \%)$ women were primigravida similar to studies from West Bengal (51.8\%). ${ }^{11}$ These findings may be due to more awareness and monetary benefits given by the government on institutional delivery.

In our study, the most common indication of CS was NPL $(45.5 \%)$ which include failure to progress along with failure of induction. There is wide variation in the CS rates due NPL. Most of the Indian studies reported NPL in the range $3 \%$ to $16 \%$ however a few studies also reported NPL as high as $25-30 \% .^{10,13}$ The likely reason for NPL to attribute higher rates of CS might be our hospital getting many patients who were induced outside and referred to our institution with inappropriate records of induction agents. Other reason may be less frequent use of oxytocin for induction of labour in our hospital. Recent studies advocate that induction of labour makes a CS more likely among primigravida in unfavourable cervix. ${ }^{20}$

The second common indication of CS was previous CS (26.2\%) comparable to $23-36 \%$ in most studies. ${ }^{6,13,17}$ In our hospital five percent women underwent VBAC which is very less and may be the likely reason for high CS rate due to previous CS. The possible reason for lesser VBAC may be unavailability of details regarding previous CS, doubtful scar strength, greater number of complicated referral cases and shortage of trained personnel for continuous monitoring of such cases. It was recommended by Royal college of Obstetricians and Gynaecologists that all women delivered by previous CS having singleton fetus 
with vertex presentation should be offered a trial of labour first. ${ }^{21}$ Studies had demonstrated that good selection of women for VBAC would reduce CS rate from 70.4 to 25.5 percent. $^{22}$

Fetal distress (FD) is found to be third commonest cause of CS in our study. Most of the studies found FD attribute CS in $10-20 \%$, comparable to our study ${ }^{17}$ whereas a few studies from West Bengal, Assam and Nepal reported FD as high as $34 \% .^{6,13}$ Continuous cardiotocography (CTG) was done to detect FD in these institutions. Studies have shown that monitoring of the fetal heartbeat in labour using CTG was found to be associated with increased rates of $\mathrm{CS}^{23}$ The gold standard test to assess the FD is fetal scalp $\mathrm{pH}$ measurement which was not done in these institutions. Cephalo-pelvic disproportion (CPD) found as a fourth common cause of CS similar to previous studies. ${ }^{17}$ In a multicentric study showed decrease in perinatal mortality and morbidity for the singleton term breech baby delivered by planned CS as compared to planned vaginal birth, at the cost of increased maternal morbidity. ${ }^{24}$ However no difference in long term neurodevelopmental delay was found between planned CS compared to vaginal birth. It was suggested that planned CS should only be considered after external cephalic version has been attempted and failed. $^{25}$

The present study found $29.7 \%$ babies had low birth weight (LBW) which is similar to the study from Kolkata (30.4\%) in adult primigravida mothers. ${ }^{27} \mathrm{CS}$ is performed in LBW babies to improve perinatal outcome. Although the risk of LBW was higher in our study but it was not significant. Due to biological immaturity in teenage mothers the risk of LBW is found even with adequate perinatal care. $^{28}$

\section{Strength}

The strength of our study is large sample size focusing on the poorly served section of the society. We have reported about the feto-maternal morbidity as well as mortality.

\section{Limitations}

This study may overestimate the rates of CS as no records of home deliveries were included, hence cannot be the representation of whole community. Due to cross sectional study, no long-term complications of CS were documented. Since patients were not aware of the indication of previous CS hence no data was recorded about the indication of previous CS.

\section{CONCLUSION}

Rising rate of CS are alarming to the health policy makers to avoid unnecessary CS. Partogram of each labour and judicious use of induction agents would help in reducing the rate of CS due to NPL. VBAC should be encouraged. Meticulous interpretation of fetal heart rate recordings by cardiotocography and measurement of fetal scalp pH may help in accurate diagnosis of FD. External cephalic version should be attempted in appropriate cases might help in reducing the $\mathrm{CS}$. Proper aseptic condition and judicious use of antibiotic would help in reducing the rate of wound infection after the CS.

\section{Funding: No funding sources}

Conflict of interest: None declared

Ethical approval: The study was approved by the Institutional Ethics Committee

\section{REFERENCES}

1. WHO. Appropriate technology for birth. Lancet. 1985;2(8452):436-7.

2. Sachs BP, Kobelin C, Castro MA, Frigoletto F. The risks of lowering the cesarean-delivery rate. $\mathrm{N}$ Engl $\mathrm{J}$ Med. 1999;340(1):54-7.

3. Little SE, Orav EJ, Robinson JN, Caughey AB, Jha AK. The relationship between variations in cesarean delivery and regional health care use in the United States. Am J Obstet Gynecol. 2016;214(6):735.

4. Betran AP, Ye J, Moller AB, Zhang J, Gulmezoglu AM, Torloni MR. The Increasing Trend in Caesarean Section Rates: Global, Regional and National Estimates: 1990-2014. PLoS One. 2016;11(2):148343.

5. Kambo I, Bedi N, Dhillon BS, Saxena NC. A critical appraisal of cesarean section rates at teaching hospitals in India. Int $\mathbf{J}$ Gynaecol Obstet. 2002;79(2):151-8.

6. IIPS. National Family Health Survey, 2017. Available from: http://www.rchiips.org/nfhs. Accessed on 12 June 2021.

7. Randive B, Diwan V, Costa A. India's Conditional Cash Transfer Programme (the JSY) to Promote Institutional Birth: Is There an Association between Institutional Birth Proportion and Maternal Mortality?. PLoS One. 2013;8(6):67452.

8. Lumbiganon P, Laopaiboon M, Gulmezoglu AM, Souza JP, Taneepanichskul S, Ruyan P, et al. Method of delivery and pregnancy outcomes in Asia: the WHO global survey on maternal and perinatal health 2007-08. Lancet. 2010;375(9713):490-9.

9. Manjulatha B, Sravanthi TP. Caesarean section rates in a Teaching Hospital: a ten-year review. IOSR J Dent Med Sci. 2015;14(8):1-5.

10. Singh G, Gupta ED. Rising incidence of caesarean section in rural area in Haryana, India: a retrospective analysis. Internet J Gynecol Obstetr. 2013;17(2):1-5.

11. Mittal S, Pardeshi S, Mayadeo N, Mane J. Trends in cesarean delivery: rate and indications. J Obstet Gynaecol India. 2014;64(4):251-4.

12. Rahman H, Pradhan D. Rising trends and changed indications of caesarean sections in Sikkim, India: cause for concern? Int Reprod Contracept Obstet Gynecol. 2017;5(6):1851-6.

13. Sarkar D, Bhadra B, Saha MM, Sarkar S. Caesarean section rates in a rural tertiary care hospital in West Bengal. Med Pulse Int Med J. 2016;3(9):862-5. 
14. Sarma P, Boro RC, Acharjee PS. An analysis of indications of caesarean sections at Tezpur medical college and hospital, Tezpur (a government hospital). Int J Reprod Contracept Obstet Gynecol. 2017;5(5):1364-7.

15. Saxena N, Sharma B, Gupta V, Negi KS. A six year appraisal of caesarean delivery at a teaching hospital in Uttarakhand. Int J Reprod Contracept Obstet Gynecol. 2016;5:4369-72.

16. Preetkamal, KH, Nagpal M. Is current rising trend of cesarean sections justified?. Int J Reprod Contracept Obstet Gynecol. 2017;6:872- 6.

17. Yadav S, Kaur S, Yadav SS, Thakur B. Analysis of caesarean rate, indications and complications: review from medical college Ambala, Haryana, India. Int J Reprod Contracept Obstet Gynecol. 2016;5:3326-9.

18. Padmaleela K, Thomas V, Prasad KV. An analysis of the institutional deliveries and their outcomes in government teaching hospitals of Andhra Pradesh, India. IJHSR. 2013;3(5):76-81.

19. Banerjee B, Pandey G, Dutt D, Sengupta B, Mondal M, Deb S. Teenage pregnancy: a socially inflicted health hazard. Indian J Community Med. 2009;34(3):227-31.

20. Rayburn WF. Minimizing the risk from elective induction of labour. J Reprod Med. 2007;52:671-6.

21. Thomas J, Parenajothy S. The National Sentinel Cesarean Section Audit Report. London: RCOG Press; 2001.

22. Metz TD, Stoddard GJ, Henry E, Jackson M, Holmgren C, Esplin S. How do good candidates for trial of labor after cesarean (TOLAC) who undergo elective repeat cesarean differ from those who choose TOLAC?. Am J Obstet Gynecol. 2013;208(6):458.
23. Alfirevic Z, Devane D, Gyte GM, Cuthbert A. Continuous cardiotocography (CTG) as a form of electronic fetal monitoring (EFM) for fetal assessment during labour. Cochrane Database Syst Rev. 2017;2(2):6066.

24. Hofmeyr GJ, Hannah M, Lawrie TA. Planned caesarean section for term breech delivery. Cochrane Database Syst Rev. 2015;2015(7):166.

25. Agudelo A. Planned caesarean section for term breech delivery: RHL commentary. Geneva: WHO; 2003.

26. Hooda R, Mann S, Nanda S, Gupta A, More H, Bhutani J. Immediate Postpartum Intrauterine Contraceptive Device Insertions in Caesarean and Vaginal Deliveries: A Comparative Study of FollowUp Outcomes. Int J Reprod Med. 2016;7695847.

27. Mukhopadhyay P, Chaudhuri RN, Paul B. Hospitalbased perinatal outcomes and complications in teenage pregnancy in India. $\mathbf{J}$ Health Popul Nutr. 2010;28(5):494-500.

28. Scholl TO, Hediger ML, Salmon RW, Belsky DH, Ances IG. Association between low gynaecological age and preterm birth. Paediatr Perinat Epidemiol. 1989;3(4):357-66.

Cite this article as: Maurya $\mathrm{P}$, Saini S, Saini B, Kumar M, Adhya AK, Mondal RK. A cross sectional study to evaluate indications and outcomes of caesarean section in a district hospital of West Bengal. Int J Reprod Contracept Obstet Gynecol 2021;10:3072-8. 